\title{
Presidential Views: Interview with Eric Friedlander
}

Every other year, when a new AMS president takes office, the Notices publishes interviews with the outgoing and incoming presidents. What follows is an edited version of an interview with Eric M. Friedlander, whose two-year term as president ends on January 31, 2013. Friedlander is Dean's Professor of Mathematics at the University of Southern California, and Henry S. Noyes Professor of Mathematics, emeritus, at Northwestern University. The interview was conducted in fall 2012 by Notices senior writer and deputy editor Allyn Jackson.

An interview with president-elect David Vogan will appear in the March 2013 issue of the Notices.

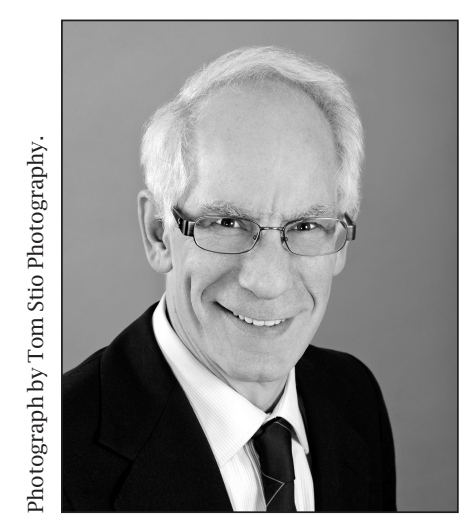

Eric Friedlander
Notices: One controversial issue that arose during your presidency was the Engage to Excel report by PCAST [President's Council of Advisors on Science and Technology]. The Notices had two articles about this report in the October 2012 issue. What is the current status?

Friedlander: PCAST operates within the Office of Science and Technology Policy. Once a report is published, PCAST shifts its focus to other topics. Its most recent report is entitled Propelling Innovation in Drug Discovery, Development, and Evaluation. The report Engage to Excel will remain in place, and it will continue to have an influence on those concerned with the education of students aiming for STEM [science, technology, engineering, and mathematics] careers. There may be some new federal funding that will support some of its recommendations, and there are influential scientists who press the point of view in this report.

The PCAST report-which, in my view, is extremely unfair, unbalanced, and uninformed about what the mathematical community is doing-nonetheless could be seen as constructive and useful. It served as a wake-up call. In most colleges and universities, mathematicians are trying various ways of reaching out to students who have weak mathematics backgrounds or who are undermotivated and of reaching out to other disciplines that wish their students to have certain mathematical skills or information. We should be doing more, and we should have a repository of information about what we are doing, but I don't think the solution is to be found in some special teaching

DOI: http://dx.doi.org/10.1090/noti956 technique that would suddenly make us all great teachers. We need a more fundamental assessment of the future of mathematics education. I would like to see the AMS and the mathematics community shine a brighter light on what we can do and how we publicize what we are doing in mathematics education.

My concern with the PCAST report philosophically was this. We have to worry about not just the need for one million new STEM graduates-not just the increased numbers-but the quality of the education we offer and the knowledge students acquire. That message gets lost if you emphasize so much that we need to increase the numbers. The solution is not to dumb down the mathematics presented or to remove mathematics from the curriculum. We need to include and embrace as many people as possible. If we don't, the basis of science will shrink to nothing. At the same time, we can't say that certain aspects of science are too difficult or should be left for only a few elite people.

Notices: Another issue that came up during your presidency is "gold open access" publishing. Can you describe what gold open access is and how it might affect the math community and the AMS?

Friedlander: This is a really big deal. It concerns the AMS considerably. "Gold open access" means the author pays the cost of publication. "Open access" means that, once published, the publication is freely available, usually on the Web. In the current model, libraries pay a great deal of money to subscribe to journals, and that's how journals are supported. Gold open access turns this around and makes that support come from authors.

This movement is related to the National Institutes of Health stipulation that work coming out of its grants should be made freely available shortly after publication-six months, or something like that. Although the details are not clear, both Britain and Germany seem to be suggesting that if you get 
national government funds, you should publish articles in gold open access journals. That's really dramatic.

Also wrapped up in this is the Elsevier boycott, which involved many prestigious mathematicians, including Timothy Gowers and Terence Tao. The boycotters asserted that Elsevier was making much too much money and was behaving badly, so we should avoid working with Elsevier and should find new ways of publishing. One recent development is the creation of two new journals at Cambridge University Press, called Sigma and Pi. They will be electronic only and open access, and for the first three years CUP will absorb all costs. After that the journals will be based on the author-pay model.

This model is extremely tricky for the mathematics community. One hope is that mathematicians will get grant funds to cover author costs, which might be on the order of US\$2,000 per article. At the moment, almost no grants have such funds. Another hope is that universities will say, "We now have lower subscription costs for libraries, so we'll pass the savings down to individual departments, which will pass them down to individual faculty, who can use the money to pay publishing costs." Some of us who have observed how university finances work doubt that that's going to happen. A third possibility is that people will just pay out of their own pockets. If you want to get a job, if you want to get tenure, if you want to get promoted, if you want to get recognized, then you need publications. And you will pay for them. That one would need to be able to bankroll one's career would be extremely unfortunate. I get one or two ads a week asking me to publish in open access journals - they are sprouting up all over the place, and they are strictly money making. A lot of vanity presses are seeking to exploit scientists' need to publish. So there are real concerns about the author-pay model.

Mathematics is in a very awkward position because we are a small science. Many of us work by ourselves or maybe with one or two other people. Many of us work without grants. In areas such as biology or medicine, the grants are large and have publication funds. The sad thing is, governments may make decisions based on the dominant role of the biological and medical sciences. That's where most of the money and the numbers are. Mathematics will probably have to go along with the decision of governments about gold open access, even though what's best for biology is not necessarily what's best for mathematics. It really is a quandary for us. At the moment, we are scrambling to position ourselves to comply with whatever governments stipulate. The AMS has made strong statements that we would not base a decision about acceptance of a paper on the ability of the author to pay.
Notices: One issue within the AMS that came up during your term is the Fellows Program. What is your sense of the reaction within the math community?

Friedlander: Most people are very enthusiastic. There was a minority from the beginning who called it an elitist program and didn't like recognizing people who, from their point of view, had already been recognized. I've heard a few disgruntled comments but also many enthusiastic comments. I already know from my own university that this is going to give local recognition to mathematics. So I think the response is going to be very positive. The immediate response to the process of naming fellows has been that some people realize that their membership has lapsed; they would have qualified to be in the initial seed pool to become fellows, but they are no longer members. Messages from such excellent mathematicians show the value of the Fellows Program in the eyes of many.

Notices: If such people reinstate their membership, can they become fellows?

Friedlander: Yes, but it is not automatic. To start the program, a large number of mathematicians will become inaugural fellows in 2012, typically because they gave an International Congress of Mathematicians talk or an ICIAM [International Congress of Industrial and Applied Mathematics] plenary talk or an AMS invited address. Also, they must have been members for the last two years. Beginning in 2013, there will be a Fellow Selection Committee consisting of current fellows, and the committee composition will change every year. They will use whatever criteria they see fit to choose new fellows. But it will not be the case that those people who were not members but would otherwise have qualified to be inaugural fellows would automatically be in the next year.

I think the Fellows Program is good for mathematics and good for mathematicians. One thing I am very concerned about is membership, and I think the program is going to bolster membership in the AMS. A few people are going to resign because they object to the Fellows Program, but many more will join because they want to become fellows. You can't be a fellow without being a member. Also, they'll feel some identification with the AMS because they are fellows.

Notices: Another new program is the AMS graduate student chapters. How do they work?

Friedlander: We've identified, I think, twelve chapters to start in 2012. It will soon probably be over one hundred. A group of students with a faculty leader will write to the AMS and say, "We'd like to be an AMS chapter." The AMS will respond and say, "Great, welcome aboard, and here is US\$500 that you can spend on pizzas or movies or inviting speakers." We hope to keep the bureaucracy to a minimum and to make the chapters a focus for graduate students in departments. Also, it will be 
a link between the AMS and those who lead the chapters.

One thing I have found very striking is that we have many graduate student members-they used to be called nominee members-and yet, when I would visit various universities, the students didn't know they were members. We are hoping the student chapters will make students more aware of the AMS and begin to get involved with the AMS. We also hope the chapters can help to create a good atmosphere in departments for graduate students. This is not a new idea. Other mathematical organizations already have student chapters. The AMS at the present time is in a sufficiently sound financial situation that it can offer small amounts of money to further support student activities.

Another thing we are starting is activity groups. This is something SIAM [Society for Industrial and Applied Mathematics] has had for many years. In fact, SIAM members often identify themselves more with their activity group than with SIAM itself. There has been a lot of discussion within the AMS, and the concept for the AMS activity groups has been changing over time.

Notices: What is the current idea of how it might work?

Friedlander: The current idea is to make it completely virtual, perhaps a combination of social networking and MathOverflow, based on people's areas of interest. MathOverflow can be a little intimidating, because it rates the quality of people's postings. The AMS model would be more informal. Although it would not be feasible for all the activity groups to meet at sectional or national meetings, one or two groups could get together and decide to organize one or two special sessions at an AMS meeting or to get together for lunch or dinner. The idea is to make it simple in concept and simple to run. The groups would provide an organization in which people with similar mathematical interests can get together virtually.

Notices: Is there anything else that the AMS is doing that you would like to talk about?

Friedlander: We have established an AMS Committee on Women in Mathematics. I hope this committee will have some financial resources behind it and can make specific recommendations. There is already a Joint Committee on Women with maybe eight mathematical organizations participating in it. That committee is a good nexus, but it doesn't really have the ear of the AMS. I hope the new committee will.

I also want to mention how good the AMS staff is, from the leaders, like Don McClure, all the way down. They are remarkably dedicated, and it's an amazingly good organization. Ideas get carried out. What I've found is that I have to be very careful not to propose too many things, because there could be gridlock!
One thing I would like to see us do is to have more contact with and influence in state and federal government. Maybe mathematics is too small to have a lot of influence, but I think we can do more. There are many other things I could tell you, but this is more than enough!

Notices: One last question. During your term as president, you talked to many mathematicians about the state of mathematics and the math profession. What are your impressions of the biggest problems, and the biggest successes, in the field right now?

Friedlander: The successes in the field are fantastic theorems, important theorems, applications of mathematics - the scientific successes.

But there are lots of worries about the overall health of the mathematical community. I am particularly worried about mathematics education at the university level. There is a lot of skepticism out there, and not just from the PCAST report. We need to think about how we're going to teach and reach out to people who need mathematics. Some of them are interested in mathematics, some will become mathematicians - and some of them are not interested in mathematics but still need mathematics. If the AMS can help in the process of calling attention to good practices for doing this and being a reservoir of information and materials, that would help a lot. Another aspect is MOOCs, massive open online courses. Who knows how that's going to influence mathematics teaching? Maybe one professor who normally teaches computer science will instead teach 500,000 students first-year calculus through a MOOC. Students don't learn that way, and we mathematicians have to say so. We have to be aware that education doesn't stand still.

I also see more and more that fundamental research is under threat. The NSF [National Science Foundation] now has grants that are specifically not to support research but to support the translation of research into the marketplace. It used to be that the NSF was the one place in the U.S. federal government that supported fundamental research. It still does, but it's broadening its mission. There is a view of some that mathematics is fine-provided it informs investigations of, for example, genetics. We have to make the case that mathematics itself, and not just applications, is very important. Maybe the need to make this case has been there for millennia; maybe now is not a special time. But I'm more aware of this need now than I had been. 